\title{
Enhanced in vitro production of diosgenin in shoot cultures of Dioscorea deltoidea by elicitation and precursor feeding
}

\section{Romaan Nazir}

Lovely Professional University Department of Biotechnology

\section{Suphla Gupta}

Council of Scientific \& Industrial Research Indian Institute of Integrative Medicine

\section{Vijay Kumar}

Lovely Professional University Department of Biotechnology

\section{Ajai Prakash Gupta}

Council of Scientific \& Industrial Research Indian Institute of Integrative Medicine

\section{Padmanabh Dwivedi}

banaras hindu university

\section{Abhijit Dey}

Presidency University Kolkata

\section{Tabarak Malik ( $\nabla$ malikitrc@gmail.com )}

University of Gondar College of Medicine and Health Sciences https://orcid.org/0000-0002-8332-7927

\section{Devendra Kumar Pandey}

Lovely Professional University Department of Biotechnology

\section{Research article}

Keywords: D. deltoidea, diosgenin, elicitors, gas chromatography-mass spectrometry, precursors

Posted Date: December 3rd, 2020

DOl: https://doi.org/10.21203/rs.3.rs-41829/v2

License: (c) (1) This work is licensed under a Creative Commons Attribution 4.0 International License. Read Full License 


\section{Abstract}

Background: Dioscorea deltoidea (Family: Dioscoreaceae) is a critically endangered medicinal plant widely used in traditional medicine and pharmaceutical industries for the preparation of appropriate drugs. The present study was conducted to investigate the effect of different elicitors such as salicylic acid (SA), methyl jasmonate (MeJa), jasmonic acid (JA) and abscisic acid (ABA) on the synthesis of diosgenin production in $D$. deltoidea shoot cultures. In addition, the effect of different precursors (squalene, $\beta$-sitosterol, and cholesterol) was also demonstrated.

Results: Results showed that precursors significantly influenced diosgenin production as compared to elicitors. Application of SA $(200 \mu \mathrm{M})$ showed highest diosgenin production $(0.912 \% \mathrm{DW})$ following $4 \mathrm{~h}$ of incubation time, whereas MeJA $(100 \mu \mathrm{M})$ exhibited $0.814 \%$ DW of diosgenin content following $8 \mathrm{~h}$ of incubation time. Among precursors, $\beta$-sitosterol at $200 \mu \mathrm{M}$ produced maximum diosgenin content $(1.006 \%$ DW $)$ followed by $100 \mu \mathrm{M}$ squalene $\left(0.947 \%\right.$ DW) harvested after $5^{\text {th }}$ day of the precursor addition. Interestingly, cholesterol showed low diosgenin production, but significant than control cultures. Finally response surface methodology (RSM) was conducted to see the interactive effect of best elicitors and precursors concentration for better yield of diosgenin and biomass.

Conclusions: The results revealed that exposure to different elicitors and precursors have a significant influence on accumulation of diosgenin in $D$. deltoidea shoot cultures. The optimized conditions for SA and $\beta$-sitosterol for the better yield of diosgenin and biomass were found to be $165 \mu \mathrm{M}, 150 \mu \mathrm{M}$ and 170 $\mu \mathrm{M}, 140 \mu \mathrm{M}$ respectively.

\section{Background}

Plants synthesize a diversity of structurally complex bioactive compounds commonly known as secondary metabolites. Bioactive compounds do have an important role in bio pesticides, food, cosmetics and pharmaceutical industries [1]. Different members of Dioscoreaceae family have acquired significant economic interest owing to their therapeutic value and pharmacological efficacies. Globally, they are also considered as rich sources of important bioactive compounds used in traditional medicine and pharmaceutical industry [2]. Dioscorea deltoidea Wall (Family: Dioscoreaceae) is an important therapeutic plant growing in tropical and sub-tropical regions of the world including the north-western Himalayas of India [3]. It has a long and rich history in traditional as well as advance medicinal fields. This plant species contains many bioactive compounds such as diosgenin, stigmasterol, $\beta$-sitosterol and campesterol $[4,5]$. In the past few decades, diosgenin has been utilised commercially as a precursor for the preparation of sex hormones, contraceptives and other steroidal hormones [6]. Diosgenin has also demonstrated various therapeutic and preventive properties against cardiovascular ailments, allergic diseases, skin aging, neurodegenerative diseases and menopausal symptoms [7, 8]. It attributes to anticancerous, anti-diabetic, anti-fungal, anti-microbial, anti-thrombosis and anti-coagulation effects [9 - 12]. Due to its high usage and illegal harvesting, the wild population and genetic diversity of the species is rapidly declining. Furthermore, variations in climate and environment conditions also modulate the 
chemical profile of $D$. deltoidea especially the wild ones. Since plant tissue culture (PTC) techniques are considered as an excellent ex-situ conservation strategy of natural genetic resources, it is considered as favourable choice for the production of such valuable bioactive compounds to fulfil its pharmaceutical demand throughout the year without facing any seasonal restrictions [13 - 19]. PTC is significantly important for endangered and rare species since it facilitates biomass production without any deleterious effect on natural populations $[20,21]$. In vitro production of bioactive compounds could be improved by using different strategies like biotic/abiotic elicitation, precursor feeding, manipulation of plant growth regulators (PGRs) and media type, carbon and nitrogen source etc. [13, 22, 23]. Among these strategies, elicitation and precursor feeding are the innovative approaches for the synthesis and production of secondary metabolites when provided in suitable amounts to in vitro cultures [24,25]. Various factors like concentration and selectivity of elicitor and precursor, exposure time and culture age are important parameters affecting successful and significant production of secondary metabolites [26]. Elicitors like benzoic acid, methyl jasmonate (MeJa), salicylic acid (SA), chitosan, jasmonic acid (JA) etc. and precursors such as progesterone, cholesterol, squalene, alanine, phenylalanine, mevalonic acid, shikimic acid etc. have been reported to increase the amount of phenolics, flavonoids, triterpenoids, alkaloids, anthocyanins etc. in callus cultures, cell suspension cultures as well as in organ cultures of many plant species [27 - 30]. In cell or organ cultures, SA and MeJa were found to be effective to initiate the production of secondary metabolites. It is considered that MeJa takes part in the pathway of signal transduction that makes specific enzymes to catalyse biochemical reactions for the formation of compounds with low molecular weight like polyphenols, polypeptides, terpenoids, alkaloids and quinones [31]. SA is considered as a key-signaling molecule responsible for the stimulation of defence responses in plants [32]. In D. deltoidea, diosgenin is biosynthesized by mevalonate pathway and squalene, $\beta$-sitosterol and cholesterol are the intermediate precursors. Cell suspensions or organ cultures precursor feeding in a metabolic pathway has produced large amount of bioactive compounds [33]. In this present study, influence of the elicitors (MeJa, SA, JA, ABA) and precursors (squalene, $\beta$-sitosterol and cholesterol) were analysed on diosgenin production from in vitro shoot cultures of $D$. deltoidea. To the best of our knowledge, current study is the first attempt to elucidate the influence of elicitors and precursors on diosgenin production in $D$. deltoidea shoot cultures.

\section{Results}

\section{Screening of efficient elicitors}

Various effects of individual elicitors on the diosgenin yield from the in vitro shoots were observed. Compared to the control group ( $0.264 \pm 0.03 \%$ diosgenin ; biomass: $1.73 \pm 0.32 \mathrm{~g})$, Me-J and SA showed most promising effects with $0.334 \pm 0.13 \%$ diosgenin; biomass: $07.73 \pm 0.42 \mathrm{~g}$ and $0.434 \pm 0.13 \%$ diosgenin; biomass: $1.73 \pm 0.042 \mathrm{~g}$ respectively while $\mathrm{JA}$ and $\mathrm{ABA}$ demonstrated marginal enhancement on diosgenin yield ( $0.284 \pm 0.023 \%$ diosgenin; biomass: $1.13 \pm 0.22 \mathrm{~g}$ and $0.234 \pm 0.23 \%$ diosgenin; biomass: $0.73 \pm 0.032 \mathrm{~g}$ ) respectively. Thus, Me-J and SA displayed enhanced efficiency as elicitors and were further selected to enhance the production of bioactive compounds. 


\section{Effect of elicitors on shoot biomass accumulation of D.deltoidea}

The effect of SA and MeJa was determined on growth rates and biomass accumulation in D. deltoidea shoot cultures. Different concentration of SA and MeJa (100,200 $\mu \mathrm{M})$ were added separately to the liquid medium with different incubation times (4-16 h) respectively on $5^{\text {th }}$ week of culture. Table 1 displays biomass production of shoot cultures treated with SA and MeJa after 10 days. Shoots elicited with MeJa showed reduced biomass production following 4 and $16 \mathrm{~h}$ of incubation time but the biomass increased after $8 \mathrm{~h}$ of elicitation. MeJa $(200 \mu \mathrm{M})$ reduced biomass production as compared to control cultures while cultures elicited with SA also showed similar pattern of biomass reduction.

\section{Effect of elicitors on diosgenin production in D. deltoidea shoot cultures}

The effect of SA and MeJa on the diosgenin content in D. deltoidea shoots is shown in Table 1. In order to stimulate diosgenin production, shoot cultures were exposed to elicitor treatment, which is considered as one of the effective strategies to enhance the secondary metabolite production. The present study showed remarkable differences in diosgenin production in shoot cultures treated with elicitors (MeJa and SA) at different incubation times (Table 1). The diosgenin content was significantly increased in all the treated cultures as compared to control. It was found that the addition $100 \mu \mathrm{M}$ MeJa with $8 \mathrm{~h}$ incubation time induced an increase in diosgenin production $(0.814 \% \mathrm{DW})$. In this study, incubation time showed significant role in upregulating the diosgenin content in $D$. deltoidea shoot cultures; $8 \mathrm{~h}$ and $100 \mu \mathrm{M} \mathrm{MeJa}$ was observed to be optimum for the production of diosgenin while $4 \mathrm{~h}$ of incubation time for SA (200 $\mu \mathrm{M}$ ) exhibited better yield under in vitro conditions.

\section{Effect of precursors on biomass accumulation in $D$. deltoidea shoot cultures}

Precursors such as squalene, cholesterol and $\beta$-sitosterol, correlated to the biosynthesis of diosgenin, when supplemented in shoot cultures of $D$. deltoidea showed significant reduction in biomass accumulation (Table 2). The precursors treated shoots' biomass remained in range of 0.517 to $1.559 \mathrm{~g}$ of DW while in the control the biomass was $1.77 \mathrm{~g}$. Squalene showed insignificant biomass reduction when cultures were harvested after $5^{\text {th }}$ day but biomass accumulation was significantly reduced in both concentrations when harvesting was done after $10^{\text {th }}$ day. In case of cholesterol, there was biomass reduction at both concentrations. $\beta$-sitosterol at $100 \mu \mathrm{M}$ concentration showed insignificant biomass reduction after $5^{\text {th }}$ day of harvesting, whereas $200 \mu \mathrm{M}$ concentration of $\beta$-sitosterol greatly affected biomass accumulation.

\section{Effect of precursors on diosgenin production in $D$. deltoidea shoot cultures}

Gas chromatography-mass spectrometry (GC-MS) analysis confirmed that $\beta$-sitosterol significantly influenced the diosgenin content when compared to other precursors. Our results indicated that $100 \mu \mathrm{M}$ of squalene induced upregulation of diosgenin production $(0.947 \%$ DW) for 5 days followed by $200 \mu \mathrm{M}$ of squalene $(0.636 \% \mathrm{DW})$ for 5 days as compared to control $(0.319 \% \mathrm{DW})$. It was found that diosgenin content was significantly reduced with the increase of harvesting time. Squalene $(200 \mu \mathrm{M})$ yielded lowest 
diosgenin content $(0.412 \% \mathrm{DW})$ after 10 day of exposure time. In addition, $\beta$-sitosterol also greatly affected diosgenin content in $D$. deltoidea shoot cultures. Our results suggest that $\beta$-sitosterol $(200 \mu \mathrm{M})$ was critical for diosgenin synthesis and maximum content $(1.006 \% \mathrm{DW})$ was found on $5^{\text {th }}$ day of exposure time followed by $100 \mu \mathrm{M} \beta$-sitosterol $(0.782 \% \mathrm{DW})$. After 10 days of time, diosgenin content was significantly reduced as exposure period played an important role in diosgenin production. Cholesterol showed less effect on diosgenin production as compared to squalene and $\beta$-sitosterol. Cholesterol $(200 \mu \mathrm{M})$ for 5 days showed optimum diosgenin content $(0.635 \% \mathrm{DW})$ followed by cholesterol $(100 \mu \mathrm{M})$ for 5 days $(0.562 \% \mathrm{DW})$. In all the cases, 10 days harvesting time showed least diosgenin production.

\section{Experimental design and statistical optimization by RSM}

Thirteen experiments were designed using different combination of salicyclic acid (SA) and $\beta$-sitosterol and the results of responses were studied with respect to biomass and diosgenin content. The above experiments formed the basis for parameter evaluation of the models for diosgenin content [Eqs. (1)] and biomass [Eq. (2)]. These model equations were solved for different concentrations of SA and $\beta$-sitosterol. The contour plots emerging out of above analysis are described in the Fig. 3(a)-(b).

(1) $Y_{1}($ Diosgenin yield $)=+1.3026-0.87 \times A+0.067 \times B-0.146 A^{2}-0.115 B^{2}-0.103 A * B$

(2) $\mathrm{Y}_{2}$ (Biomass) $=+1.954-0.008 \mathrm{~A}+0.012 \mathrm{~B}-0.028 \mathrm{~A}^{2}-0.019 \mathrm{~B}^{2}+0.0005 \mathrm{AB}$

where $A$ = salicyclic acid, $B=\beta$-sitosterol,

ANOVA results obtained for linear, quadratic, and interaction of all the independent variables are presented in Table 4A. The probability value ( $P$-value) was considered highly significant that showed less than 0.01 values whereas values less than 0.05 were significant and were considered in quadratic equation whereas $P$-value more than 0.05 were non-significant and were not considered in the quadratic equation. The determination coefficients $\left(R^{2}\right)$ of 99.17 and 99.1 , for diosgenin yield and biomass, respectively indicated that the model could be used to explain all the variations.

The linear effect of salicyclic acid $(A)$ and $\beta$-sitosterol were found to be positively statistically significant $(p \leq 0.001)$ for diosgenin yield (Table 4B ). As far as biomass was concerned, salicyclic acid showed negative and $\beta$-sitosterol exhibited positive linear significant effect. The negative quadratic effects of SA $\left(A^{2}\right)$ and $\beta$-sitosterol $\left(B^{2}\right)$ confirms the deceleration of the diosgenin as well as biomass yield. The interactions between $A B$ (salicyclic acid and $\beta$-sitosterol), for diosgenin yield was negatively significant, while for biomass it was non-significant.

The contour plot graph depicts the major effects of all the independent variables for the yield of diosgenin and biomass were represented in Fig. $3 \mathrm{~A}$ and 3B respectively. The optimized conditions [salicyclic acid (A) and $\beta$-sitosterol (B)] for the better yield of diosgenin and biomass were found to be 165 $\mathrm{mM} ; 150 \mathrm{mM}$ and $170 \mathrm{mM}$ and $140 \mathrm{mM}$ respectively. At these optimum parameters, predicted maximum 
yield obtained for diosgenin and biomass were found to be $1.32 \%$ and $1.957 \mathrm{~g}$ which were close to their predicted value of $1.3 \%$ and $1.96 \mathrm{~g}$.

\section{Discussion}

\section{Effect of elicitors on diosgenin and shoot biomass accumulation of D.deltoidea}

The results were inconsistent with Hypericum hirsutum and Hypericum maculatum shoot cultures, in which jasmonic acid (JA) at higher concentration significantly inhibited biomass production and SA influenced biomass production slightly in relation to control [34]. Recently, Jirakiattikul et al. [35] also indicated JA to have minor effect on $D$. membranacea shoot cultures, whereas SA demonstrated no effect at all. In another study, it was found that MeJa reduced the growth of Centella asiatica culture at concentrations above $0.1 \mathrm{mM}$ [36]. In Andrographis paniculata, biomass production was adversely effected by various concentrations of SA $(10,20,50$ and $100 \mu M)$ [37]. Sivanandhan et al. [38] also reported that MeJa at 150-250 $\mu \mathrm{M}$ completely inhibited biomass production but SA application showed insignificant reduction in biomass as compared to control. Elicitor retardation was also found in other plant cell cultures such as Salvia miltiorrhiza [39], Panax ginseng [31] and Rubia cordifolia [40]. These results suggest that growth response to different elicitors may vary among different plant species.

This suggested that elicitor used and its concentrations play an important role on the effectiveness of elicitation. In previous studies, it was reported that MeJa has increased furanocoumarin production in Ruta graveleons shoot cultures and asiaticoside production in Centella asiatica whole plant culture [41, 36]. Mendoza et al. [28] reported that elicitation with $3 \mu \mathrm{M}$ MeJa increased phenolics and flavonoids content in Thevetia peruviana suspension cultures. The production of psoralen was enhanced when MeJa and SA at $100 \mu \mathrm{M}$ were added to the suspension culture of Psoralea corylifolia [42]. Therefore, MeJa has been well established as a key signal compound which was positively involved in the signal transduction pathway that leads to secondary metabolite production [43,35]. Diosgenin production was also favoured by SA which is a widely studied signaling molecule to trigger secondary metabolite production in plants [44]. SA is generally produced in plants and accumulated at pathogen attack sites, and then spreads to several plant parts triggering the biosynthetic pathways for accumulation of secondary metabolite production [45]. This is an agreement with Diwan and Malpathak [41] and Coste et al. [34] who reported that $200 \mu \mathrm{M} \mathrm{SA}$ increased the furanocoumarin production in Ruta graveolens shoot cultures and hypericin and pseudohypericin content in Hypericum maculatum shoot cultures. However, 50 $\mu \mathrm{M}$ SA significantly reduced the diosgenin accumulation in micro-tubers of Chlorophytum borivilianum [46]. In Hypericum perforatum, the hyperforin production was increased in shootlet meristem cultures when treated with $1 \mathrm{mM}$ of SA [47]. In in vitro shoot cultures of Swertia paniculata SA promoted amarogentin, swertiamarin and mangiferin yield at optimal concentrations [48]. In the present study, the diosgenin production attained through elicitation of $D$. deltoidea shoot cultures was higher than reported in the field plants $(0.428 \%$ DW root) [49]. Considering the diosgenin accumulation observed in the elicited shoots, $D$. deltoidea is undoubtedly a potential industrial plant for the production of valuable bioactive compounds. 


\section{Effect of precursors on diosgenin and shoot biomass accumulation of D.deltoidea}

Sivanandhan et al. [27] reported that squalene and cholesterol reduced biomass accumulation in Withania somnifera suspension cultures. In another report, it was found that biomass production was decreased due to the addition of squalene and cholesterol in shoot cultures of Digitalis purpurea [12].

Squalene at $6 \mathrm{mM}$ produced highest withanolides in Withania somnifera cell suspension culture [28]. In shoot cultures of Digitalis purpurea, cardiotonic glycosides production was greatly affected by squalene and cholesterol but were less effective than progesterone [12]. Ciura et al. [49] reported that squalene and $\beta$-sitosterol treatments were responsible for more expression of gene than cholesterol treatment hence leads to enhance biosynthesis of diosgenin.

\section{Interartive effect of elicitors and precursors on diosgenin and biomass production in Dioscorea deltoidea}

Ali et al. (44) reported that methyl jasmonate and salicyclic acid enhanced the production of ginsenosides in Panax ginseng. Kaur et al. (48) also reported better yield of secoiridoid and xanthone glycosides in Swertia paniculata after optimizing the salicyclic acid and chitosan by RSM. Ciura [49] reported the role of methyl jasmonate and precursor on biosynthesis of diosgenin.

\section{Conclusions}

This work demonstrated that the elicitation practice using exogenous elicitors could significantly improve the pharmacologically active diosgenin content in shoot cultures of $D$. deltoidea as compared to control. The results of the current study also suggest that type, concentrations and exposure time of different elicitors and precursors used in this study, remarkably stimulate the diosgenin content in $D$. deltoidea shoot cultures. Among the different elicitors used, SA significantly influenced the concentration of diosgenin in $D$. deltoidea shoot cultures. The results revealed that $\beta$-sitosterol acted as a potent precursor and elicited highest amount of diosgenin as compared to squalene and cholesterol. Finally, RSM was incorporated to optimize the best concentration of salicyclic acid and $\beta$-sitosterol for maximum yield of diosgenin and biomass production. The study provides valuable insights into the potential manipulation of precursors for large scale production of diosgenin. In addition, current findings also provide a reference for enabling the scale-up production of valuable compounds by the aid of bioreactor system. Moreover, further studies are crucial to design metabolic engineering approaches that would enhance the synthesis of valuable bioactive compounds in in vitro cultures.

\section{Materials And Methods}

\section{Chemicals and reagents}

Squalene, cholesterol, $\beta$-sitosterol, salicylic acid, methyl jasmonate, jasmonic acid, abscisic acid (ABA) and standard diosgenin ( $>99 \%$ purity) were procured from Sigma-Aldrich, USA. HPLC grade chemicals like ethanol, hydrochloric acid, chloroform and analytical grade methanol were procured from HiMedia 
Laboratories Pvt. Ltd. (India). Plant growth regulators such as $\mathrm{N}^{6}$-benzyladenine (BA) and Indole-3-butyric acid (IBA) were purchased from Sigma-Aldrich, India.

\section{Plant material and culture conditions}

Mother plants of $D$. deltoidea were collected in the month of July, 2017 from Baramulla, Kashmir located at an elevation of $1690 \mathrm{~m}$. The authentication of plant species was done by the curator, submitted the specimen in KASH Herbarium, Centre for Biodiversity and Taxonomy, University of Kashmir (Voucher Specimen No. 2614-KASH).

\section{Explant selection and sterilization}

Healthy shoots obtained from mother plants were kept in greenhouse. The explants were rinsed in running tap water (10 min), followed by washing in tween-20 (10 min) and finally washed with distilled water thrice. Surface sterilization of explants was performed inside the laminar air flow chamber with 0.1 $\%(\mathrm{w} / \mathrm{v})$ of mercuric chloride $\left(\mathrm{HgCl}_{2}\right)$ for $3 \mathrm{~min}$ and then thoroughly rinsed with sterilized distilled water in order to remove the $\mathrm{HgCl}_{2}$ traces. Sterilized nodal segments were carved into proper size $(1.5-2.0 \mathrm{~cm})$ before inoculation.

\section{Culture conditions and shoot initiation}

Nodal segments were inoculated onto the Murashige and Skoog (1962) medium supplemented with $3 \%$ sucrose, $0.8 \%$ agar (w/v), BA $(2.0 \mathrm{mg} / \mathrm{l})$ and IBA $(1.5 \mathrm{mg} / \mathrm{l})$ for direct shoot organogenesis. The $\mathrm{pH}$ of the medium was adjusted to 5.8 with $1 \mathrm{~N} \mathrm{NaOH}$ or $1 \mathrm{~N} \mathrm{HCl}$. The medium was autoclaved at $121^{\circ} \mathrm{C}$ for 15 minutes. The cultures were maintained at $\left(25 \pm 2{ }^{\circ} \mathrm{C}\right)$ with photoperiod $(16 \mathrm{~h} \mathrm{light} / 8 \mathrm{~h}$ dark) and photosynthetic photon flux (PPF) of $40-50 \mu \mathrm{mol} \mathrm{m}^{-2} \mathrm{~s}^{-1}$ provided by cool white fluorescent tubes. After 21 days, plantlets were transferred into liquid MS medium with similar composition of PGRs for 5 weeks and then used for further process. Optimal harvest time was evaluated in terms of biomass accumulation at 7 weeks of culture in liquid media when plant biomass reached a maximum level of $1.95 \mathrm{~g} \mathrm{DW}(6.6 \mathrm{~g} \mathrm{FW})$ and further increase or decrease in harvest time has led to reduction of biomass accumulation.

\section{Experimental procedure}

\section{Screening of the best elicitors}

To establish an efficient elicitation strategy, the four stress elicitors salicyclic acid (SA), methyl jasmonate (MeJA), jasmonic acid (JA) and abscisic acid (ABA) were used to screen high efficient elicitors by making $100 \mu \mathrm{M}$ concentration each by dissolving them in aqueous ethanol (50\%) and filter sterilize them through a syringe filter $(0.22 \mu \mathrm{M})$. The multiple shoots $(5 \mathrm{~g} \mathrm{FW})$ was allowed to grow at different elicitors concentrations of SA $(100 \mu \mathrm{M}), \mathrm{MeJa}(100 \mu \mathrm{M}), \mathrm{ABA}(100 \mu \mathrm{M})$ and $\mathrm{JA}(100 \mu \mathrm{M})$ at exposure time duration $(4 \mathrm{~h})$ in the MS liquid media with $B A(2.0 \mathrm{mg} / \mathrm{l})$ and IBA $(1.5 \mathrm{mg} / \mathrm{l})$. The multiple shoot $(5 \mathrm{~g} \mathrm{FW})$

of $5^{\text {th }}$ week of culture were transferred to the liquid media supplemented with BA $(2.0 \mathrm{mg} / \mathrm{l})$ and IBA 
$(1.5 \mathrm{mg} / \mathrm{l})$ aseptically. After elicitation, the shoots were harvested on the $7^{\text {th }}$ week for production of biomass and diosgenin. All sets were done in triplicates and for each trial control cultures were sustained and $50 \%$ ethanol ( $\mathrm{v} / \mathrm{v})$ was used in control cultures.

\section{Effect of elicitors on biomass and diosgenin production}

SA and MeJa were used as elicitors. Stock solutions of SA and MeJa were prepared individually by dissolving them in aqueous ethanol ( $50 \%$ ethanol: $50 \%$ water $\mathrm{v} / \mathrm{v}$ ) and filter sterilize through a syringe filter $(0.22 \mu \mathrm{M})$. The multiple shoots $(5 \mathrm{~g} \mathrm{FW})$ were allowed to grow at different concentrations of SA (100 $\mu \mathrm{M}$ and $200 \mu \mathrm{M})$ and MeJa $(100 \mu \mathrm{M}$ and $200 \mu \mathrm{M})$ at different time duration $(4,8,16 \mathrm{~h})$ on $5^{\text {th }}$ week of culture with MS liquid media with BA $(2.0 \mathrm{mg} / \mathrm{l})$ and IBA $(1.5 \mathrm{mg} / \mathrm{l})$. After treatment of SA and MeJa in different time period the multiple shoots were immediately transferred to the liquid MS medium supplemented with BA $(2.0 \mathrm{mg} / \mathrm{I})$ and IBA $(1.5 \mathrm{mg} / \mathrm{l})$ aseptically. After elicitation, the shoots were harvested on the $10^{\text {th }}$ day for production of biomass and diosgenin. All sets were done in triplicates and for each trial control cultures were sustained and $50 \%$ ethanol $(\mathrm{v} / \mathrm{v})$ was used in control cultures.

\section{Effect of precursors on biomass and diosgenin production}

Squalene, $\beta$-sitosterol and cholesterol, the precursors in diosgenin pathway were used in different concentrations (100 and $200 \mu \mathrm{M})$ respectively. Stock solution of squalene, $\beta$-sitosterol and cholesterol were prepared in $99 \%$ ethanol and filter sterilized with $0.22 \mu \mathrm{M}$ of syringe filter. Filter-sterilized squalene, $\beta$ sitosterol and cholesterol were added to the liquid MS medium fortified with BA $(2.0 \mathrm{mg} / \mathrm{l})$ and IBA (1.5 $\mathrm{mg} / \mathrm{l}$ ) aseptically on the $5^{\text {th }}$ week of culture. Cultures were harvested after $5^{\text {th }}$ and $10^{\text {th }}$ day after the addition of precursor and were done in triplicates.

\section{Statistical optimization of combined addition of elicitor and precursor}

After the identification of the most potent elicitors and precursor, statistical optimization tools (Response Surface Analysis) was used to establish the optimum concentrations of the selected elicitors and precursors. These were then used as a combined strategy for enhancing the diosgenin and biomass yield. A 13 full factorial Central Composite Design (CCD) for independent variables was employed for optimization (Table 3). Filter-sterilized salicyclic acid and $\beta$-sitosterol were added to the liquid MS medium fortified with BA $(2.0 \mathrm{mg} / \mathrm{l})$ and IBA $(1.5 \mathrm{mg} / \mathrm{l})$ aseptically on the $5^{\text {th }}$ week of culture. Cultures were harvested after $10^{\text {th }}$ day. A second order polynomial model was developed based on studies of the responses of different effectors.

\section{Biomass quantification}

Fresh weight of control shoots and treated shoots were recorded after harvesting. In vitro harvested shoots were freeze-dried and lyophilized and dry weight measurement was recorded.

\section{Sample preparation}


The shoots were pulverized into a fine powder after drying and $1 \mathrm{~g} \mathrm{DW}$ of fine biomass powder of each set was macerated with aqueous ethanol $(50 \% \mathrm{v} / \mathrm{v})$ for $24 \mathrm{~h}$ at room temperature. The extract was filtered through Whatman filter paper No 1 and was dried with the help of rotary evaporator at $40^{\circ} \mathrm{C} .20 \mathrm{ml}$ of $\mathrm{HCL}(10 \%)$ was mixed to the dried residue and hydrolysed at $98^{\circ} \mathrm{C}$ for $1 \mathrm{~h}$. After cooling, chloroform (15 $\mathrm{ml}$ ) was added two times for washing and the collective mixture was extracted and isolated, lower layer i.e. chloroform layer was collected and other $20 \mathrm{ml}$ chloroform was used to extract upper layer.

Chloroform layers were combined and concentrated to dryness. An appropriate amount of methanol was added to the residue and final concentration was filtered through $0.2 \mu \mathrm{M}$ syringe filter and preserved in refrigerator $\left(4^{\circ} \mathrm{C}\right)$ for further analysis. [50]

\section{GC-MS analysis}

An Agilent 7890A gas chromatography coupled to a 5875C mass spectrometer detector (XL MSD) with triple axis and mass hunter work station software (USA) was used for the analysis of diosgenin.

Chromatography was performed on DB- $5: 30 \mathrm{~m} \times 0.25 \mathrm{~mm}$ i.d. $\times 0.25 \mu \mathrm{M}$ film thickness column. Helium works as a carrier gas at a flow rate of $0.5 \mathrm{~mL} / \mathrm{min}$. The Gas chromatography oven temperature was raised from $200{ }^{\circ} \mathrm{C}$ for $2 \mathrm{~min}$ to $280^{\circ} \mathrm{C}$ for $20 \mathrm{~min}$ at a heating rate of $10^{\circ} \mathrm{C} / \mathrm{min}$. The injection volume was $5 \mu$ using split ratio (1:1). The Mass spectra were recorded in electron impact mode with ionization energy of $70 \mathrm{eV}$ and scan rate of $0.5 \mathrm{~s} / \mathrm{scan}$ with scan range of 50-600 amu. Inlet and transfer line temperature were set $250^{\circ} \mathrm{C}$. Component identification was achieved by Wiley, NIST libraries.

Compounds were also recognized by peak enrichment on co-injection with available authentic standards. Peak area percentages were achieved electronically from the TIC response without the use of correction factors. GC-MS chromatogram of diosgenin is shown in Figure $2(a, b)$.

\section{Statistical analysis}

The values were represented in triplicates as mean \pm standard deviation. Statistical analyses were done by implementing analysis of variance (ANOVA) with Tukey's test using SPSS $(p<0.05)$.

\section{Abbreviations}

ANOVA: analysis of variance; $\mathrm{BA}: \mathrm{N}^{6}$-benzylaminopurine; DW:dryweight; GC-MS:gas chromatographymass spectrometry; IBA:indole-3-butyric acid; JA : jasmonic acid; MS: Murashige and Skoog (1962); MeJa :methyl jasmonate; PTC:plant tissue culture; PGRs : plant growth regulators; SA: salicylic acid; ABA: Abscisic acid

\section{Declarations}

Ethics approval and consent to participate: Not applicable.

Consent for publication: Not applicable 
Availability of data and materials: The datasets used and/or analysed during the current study available from the corresponding author on reasonable request.

Competing interests: The authors declare that they have no competing interests.

Funding: Lovely Professional University gave financial support but has no role in the study design, performance, data collection and analysis, decision to publish, or preparation/writing of the manuscript.

Authors' contributions: RN did the experiment, SG help in writing the paper, AD helps in collection of plant samples, AJ helped in GC-MS analysis, PD helped in statistical analysis, VK and TM did literature survey while DKP conceived the idea, and supervised the work. All authors read and approved the final Manuscript

\section{Acknowledgements}

The authors are grateful to CSIR-Indian Institute Integrative Medicine (IIIM), Jammu for providing the facilities to carry out the research work. Authors are also grateful to University of Kashmir for the authentication of Plant species.

\section{References}

1. Raomai S, Kumaria S, Kehie M, Tandon P. Plantlet regeneration of Paris polyphylla via thin cell layer culture and enhancement of steroidal saponins in mini-rhizome cultures using elicitors. Plant Growth Regul. 2015;75(1):341-53

2. Sautour M, Mitaine-Offer AC, Lacaille-Dubois MA. The Dioscorea genus: a review of bioactive steroid saponins. J Nat Med. 2007;61(2):91-101

3. Prakash A. Uses of some threatened and potential ethnomedicinal plants among the tribals of Uttar Pradesh and Uttrakhand in India. InNational Conference on Forest Biodiversity: Earth's Living Treasure 2011;(22):93-99

4. Stohs SJ, El-Olemy MM. Metabolism of progesterone by Dioscorea deltoidea suspension cultures. Phytochemistry. 1972;11(4):1397-400

5. Ishida BK. Improved diosgenin production in Dioscorea deltoidea cell cultures by immobilization in polyurethane foam. Plant Cell Rep. 1988;7(4):270-3

6. Mehrafarin A, Ghaderi A, Rezazadeh SH, NAGHDI BH, NOURMOHAMMADI G, Zand ES.

Bioengineering of important secondary metabolites and metabolic pathways in fenugreek (Trigonella foenum-graecum). J Med Plants. 2010;9:1-18

7. Jesus M, Martins AP, Gallardo E, Silvestre S. Diosgenin: recent highlights on pharmacology and analytical methodology. J Anal Methods Chem. 2016;2016:4156293

8. Yan CH, You-Mei TA, Su-Lan YU, Yu-Wei HA, Jun-Ping KO, Bao-Lin LI, Bo-Yang YU. Advances in the pharmacological activities and mechanisms of diosgenin. Chin J Nat Med. 2015;13(8):578-87 
9. Gong G, Qin Y, Huang W. Anti-thrombosis effect of diosgenin extract from Dioscorea zingiberensis $\mathrm{CH}$ Wright in vitro and in vivo. Phytomedicine. 2011;18(6):458-63

10. Raju J, Mehta R. Cancer chemopreventive and therapeutic effects of diosgenin, a food saponin. Nutr Cancer. 2008;61(1):27-35

11. He Z, Chen H, Li G, Zhu H, Gao Y, Zhang L, Sun J. Diosgenin inhibits the migration of human breast cancer MDA-MB-231 cells by suppressing Vav2 activity. Phytomedicine. 2014;21(6):871-6

12. Patil JG, Ahire ML, Nitnaware KM, Panda S, Bhatt VP, Kishor PB, Nikam TD. In vitro propagation and production of cardiotonic glycosides in shoot cultures of Digitalis purpurea by elicitation and precursor feeding. Appl Microbiol Biotechnol. 2013;97(6):2379-93

13. Murthy HN, Lee EJ, Paek KY. Production of secondary metabolites from cell and organ cultures: strategies and approaches for biomass improvement and metabolite accumulation. Plant Cell Tiss Organ Cult. 2014;118(1):1-6

14. Kumar V, Moyo M, Gruz J, Šubrtová M, Van Staden J. Phenolic acid profiles and antioxidant potential of Pelargonium sidoides callus cultures. Industrial Crops and Products. 2015;77:402-

15. Giri CC, Zaheer M. Chemical elicitors versus secondary metabolite production in vitro using plant cell, tissue and organ cultures: recent trends and a sky eye view appraisal. Plant Cell Tiss Organ Cult. 2016;126(1):1-8.

16. Ramirez-Estrada K, Vidal-Limon H, Hidalgo D, Moyano E, Golenioswki M, Cusidó RM, Palazon J. Elicitation, an effective strategy for the biotechnological production of bioactive high-added value compounds in plant cell factories. Molecules. 2016;21(2):182.

17. Dias MI, Sousa MJ, Alves RC, Ferreira IC. Exploring plant tissue culture to improve the production of phenolic compounds: A review. Ind Crops Prod. 2016;82:9-22.

18. Gonçalves S, Romano A. Production of plant secondary metabolites by using biotechnological tools. Secondary Metabolites-Sources and Applications. 2018;81-99.

19. Kikowska M, Thiem B, Szopa A, Ekiert H. Accumulation of valuable secondary metabolites: phenolic acids and flavonoids in different in vitro systems of shoot cultures of the endangered plant speciesEryngium alpinum. Plant Cell Tiss Organ Cult. 2020;141:381-91.

20. Zuzarte M, Alves-Silva JM, Alves M, Cavaleiro C, Salgueiro L, Cruz MT. New insights on the antiinflammatory potential and safety profile of Thymus carnosus and Thymus camphoratus essential oils and their main compounds. J Ethnopharmacol. 2018;225:10-7.

21. Marco-Medina A, Casas JL. In vitro multiplication and essential oil composition of Thymus moroderi Pau ex Martinez, an endemic Spanish plant. Plant Cell Tiss Organ Cult. 2015;120(1):99-108.

22. Kumar V, Chandra S. LC-ESI/MS determination of xanthone and secoiridoid glycosides from in vitro regenerated and in vivo Swertia chirayita. Physiology and Physiol Mol Bio. 2015;21(1):51-

23. Isah T, Umar S, Mujib A, Sharma MP, Rajasekharan PE, Zafar N, Frukh A. Secondary metabolism of pharmaceuticals in the plant in vitro cultures: strategies, approaches, and limitations to achieving higher yield. Plant Cell Tiss. Organ Cult. 2018;132(2):239-65. 
24. Namdeo AG. Plant cell elicitation for production of secondary metabolites: a review. Pharmacogn Rev. 2007;1(1):69-79.

25. Mulabagal V, Tsay HS. Plant cell cultures-an alternative and efficient source for the production of biologically important secondary metabolites. Int J Appl Sci Eng. 2004;2(1):29-48.

26. Ganapathi B, Kargi F. Recent advances in indole alkaloid production by Catharanthus roseus (Periwinkle). J Exp Bot. 1990;41(3):259-67.

27. Sivanandhan G, Selvaraj N, Ganapathi A, Manickavasagam M. Enhanced biosynthesis of withanolides by elicitation and precursor feeding in cell suspension culture of Withania somnifera (L.) Dunal in shake-flask culture and bioreactor. PLoS One. 2014;9(8):e104005.

28. Mendoza D, Cuaspud O, Arias JP, Ruiz O, Arias M. Effect of salicylic acid and methyl jasmonate in the production of phenolic compounds in plant cell suspension cultures of Thevetia peruviana. Biotechnol Rep. 2018;19:e00273.

29. Wang J, Li J, Wu X, Liu S, Li H, Gao W. Assessment of genetic fidelity and composition: Mixed elicitors enhance triterpenoid and flavonoid biosynthesis of Glycyrrhiza uralensis tissue cultures. Biotechnol Appl Biochem 2017;64(2):211-7.

30. Qu J, Zhang W, Yu X. A combination of elicitation and precursor feeding leads to increased anthocyanin synthesis in cell suspension cultures of Vitis vinifera. Plant Cell Tiss. Organ Cult. 2011;107(2):261-9.

31. Yu KW, Gao W, Hahn EJ, Paek KY. Jasmonic acid improves ginsenoside accumulation in adventitious root culture of Panax ginseng CA Meyer. Biochem Eng J. 2002;11(2-3):211-5.

32. Kang SM, Jung HY, Kang YM, Yun DJ, Bahk JD, Yang JK, et al. Effects of methyl jasmonate and salicylic acid on the production of tropane alkaloids and the expression of PMT and $\mathrm{H6H}$ in adventitious root cultures of Scopolia parviflora. Plant Sci. 2004;166(3):745-51.

33. Lucumi E, Vera A, Hallard D, van der Heijden R, Verpoorte R. Alkaloid formation in cell suspension cultures of Tabernaemontana elegans after feeding of tryptamine and loganin or secologanin. Plant Cell. Tiss. Organ Cult. 2002;68(3):293-9.

34. Coste A, Vlase L, Halmagyi A, Deliu C, Coldea G. Effects of plant growth regulators and elicitors on production of secondary metabolites in shoot cultures of Hypericum hirsutum and Hypericum maculatum. Plant Cell Tiss. Organ Cult. 2011;106(2):279-88.

35. Jirakiattikul $Y$, Rithichai P, Boonyeun T, Ruangnoo S, Itharat A. Improvement of dioscorealide B production by elicitation in shoot cultures of Dioscorea membranacea Pierre ex Prain \& Burkill. Mol Biol Plants. 2020:1-7.

36. Kim OT, Kim MY, Hong MH, Ahn JC, Hwang B. Stimulation of asiaticoside accumulation in the whole plant cultures of Centella asiatica (L.) Urban by elicitors. Plant cell Rep. 2004;23(5):339-44.

37. Zaheer M, Giri CC. Multiple shoot induction and jasmonic versus salicylic acid driven elicitation for enhanced andrographolide production in Andrographis paniculata. Plant Cell Tiss Organ Cult. 2015;122(3):553-63. 
38. Sivanandhan G, Rajesh M, Arun M, Jeyaraj M, Dev GK, Arjunan A, Manickavasagam M, Muthuselvam M, Selvaraj N, Ganapathi A. Effect of culture conditions, cytokinins, methyl jasmonate and salicylic acid on the biomass accumulation and production of withanolides in multiple shoot culture of Withania somnifera (L.) Dunal using liquid culture. Acta Physiol Plant. 2013;35(3):715-28.

39. Chen H, Chen F. Effect of yeast elicitor on the secondary metabolism of Ti-transformed Salvia miltiorrhiza cell suspension cultures. Plant cell Rep. 2000;19(7):710-7.

40. Bulgakov VP, Tchernoded GK, Mischenko NP, Khodakovskaya MV, Glazunov VP, Radchenko SV, et al. Effect of salicylic acid, methyl jasmonate, ethephon and cantharidin on anthraquinone production by Rubia cordifolia callus cultures transformed with the rolB and rolC genes. J Biotechnol. 2002;97(3):213-

41. Diwan R, Malpathak N. Bioprocess optimization of furanocoumarin elicitation by medium renewal and re-elicitation: a perfusion-based approach Appl Biochem Biotechnol. 2011;163(6):756-64.

42. Hari G, Vadlapudi K, Vijendra PD, Rajashekar J, Sannabommaji T, Basappa G. A combination of elicitor and precursor enhances psoralen production in Psoralea corylifolia suspension cultures. Ind Crops Prod. 2018;124:685-91.

43. Mizukami $H$, Tabira $Y$, Ellis BE. Methyl jasmonate-induced rosmarinic acid biosynthesis in Lithospermum erythrorhizon cell suspension cultures. Plant Cell Rep. 1993;12(12):706-9.

44. Ali MB, Yu KW, Hahn EJ, Paek KY. Methyl jasmonate and salicylic acid elicitation induces ginsenosides accumulation, enzymatic and non-enzymatic antioxidant in suspension culture Panax ginseng roots in bioreactors. Plant cell Rep. 2006;25(6):613-

45. Taguchi G, Yazawa T, Hayashida N, Okazaki M. Molecular cloning and heterologous expression of novel glucosyltransferases from tobacco cultured cells that have broad substrate specificity and are induced by salicylic acid and auxin. Euro J Biochem.2001;268(14):4086-

46. Chauhan R, Keshavkant S, Quraishi A. Enhanced production of diosgenin through elicitation in microtubers of Chlorophytum borivilianum Sant et Fernand. Ind Crops Prod. 2018;113:234-9.

47. Sirvent T, Gibson D. Induction of hypericins and hyperforin in Hypericum perforatum in response to biotic and chemical elicitors. Physiol Mol Plant Pathol. 2002;60(6):311-20.

48. Kaur P, Gupta RC, Dey A, Malik T, Pandey DK. Optimization of salicylic acid and chitosan treatment for bitter secoiridoid and xanthone glycosides production in shoot cultures of Swertia paniculata using response surface methodology and artificial neural network. BMC Plant Biol. 2020;20:225.

49. Ciura J, Szeliga M, Grzesik M , Tyrka M, Changes in fenugreek transcriptome induced by methyl jasmonate and steroid precursors revealed by RNA-Seq. Genomics, 2018; 110:267-276

50. Nazir R, Gupta S, Dey A, Kumar V, Yousuf M, Hussain S, Dwivedii P, Pandey DK. In vitro propagation and assessment of genetic fidelity in Dioscorea deltoidea, a potent diosgenin yielding endangered plant. S Afr J 2020 ,DOI: 10.1016/j.sajb.2020.07.018

\section{Tables}


Table 1: Effect of the elicitors on biomass accumulation and diosgenin content in shoot cultures of D.deltoidea

\begin{tabular}{cccc}
\hline \multirow{2}{*}{ Elicitor $(\mu \mathrm{m})$} & Incubationtime $(\mathrm{h})$ & \multicolumn{2}{c}{ Harvest after 10 days } \\
\cline { 3 - 4 } MeJa & & Biomass (g DW) & Diosgenin (\%) \\
\hline 0 & 4 & $1.74 \pm 0.091^{\mathrm{a}, \mathrm{b}}$ & $0.269 \pm 0.014^{\mathrm{i}, \mathrm{j}}$ \\
\hline 100 & 4 & $0.727 \pm 0.057^{\mathrm{d}}$ & $0.348 \pm 0.026^{\mathrm{g}}$ \\
\hline 200 & 4 & $0.487 \pm 0.059^{\mathrm{g}}$ & $0.432 \pm 0.013^{\mathrm{f}}$ \\
\hline 0 & & & \\
\hline 100 & 8 & $1.748 \pm 0.043^{\mathrm{a}, \mathrm{b}}$ & $0.266 \pm 0.010^{\mathrm{i}, \mathrm{j}}$ \\
\hline 200 & 8 & $0.674 \pm 0.045^{\mathrm{d}, \mathrm{e}}$ & $0.814 \pm 0.013^{\mathrm{b}}$ \\
\hline 0 & 8 & $0.632 \pm 0.031^{\mathrm{e}, \mathrm{f}}$ & $0.765 \pm 0.020^{\mathrm{c}}$ \\
\hline 100 & 16 & & \\
\hline 200 & 16 & $0.663 \pm 0.026^{\mathrm{d}, \mathrm{e}}$ & $0.533 \pm 0.018^{\mathrm{e}}$ \\
\hline & 16 & $0.523 \pm 0.024^{\mathrm{f}, \mathrm{g}}$ & $0.628 \pm 0.019^{\mathrm{e}}$
\end{tabular}

SA

$\begin{array}{cccc}0 & 4 & 1.826 \pm 0.020^{\mathrm{a}} & 0.265 \pm 0.006^{\mathrm{j}, \mathrm{j}} \\ 100 & 4 & 1.742 \pm 0.037^{\mathrm{a}, \mathrm{b}} & 0.471 \pm 0.016^{\mathrm{f}} \\ 200 & 4 & 1.664 \pm 0.038^{\mathrm{b}, \mathrm{c}} & 0.912 \pm 0.011^{\mathrm{a}}\end{array}$

$\begin{array}{cccc}0 & 8 & 1.810 \pm 0.136^{\mathrm{a}, \mathrm{b}} & 0.263 \pm 0.005^{\mathrm{i}, \mathrm{j}} \\ 100 & 8 & 1.552 \pm 0.330^{\mathrm{b}, \mathrm{c}} & 0.819 \pm 0.012^{\mathrm{b}} \\ 200 & 8 & 1.767 \pm 0.028^{\mathrm{a}, \mathrm{b}} & 0.664 \pm 0.019^{\mathrm{d}}\end{array}$

$\begin{array}{llll}0 & 16 & 1.817 \pm 0.025^{\mathrm{a}} & 0.267 \pm 0.005^{\mathrm{i}, \mathrm{j}}\end{array}$

\begin{tabular}{llll}
100 & 16 & $1.656 \pm 0.1946^{\mathrm{b}}$ & $0.625 \pm 0.007^{\mathrm{d}}$ \\
200 & 16 & $1.539 \pm 0.0223^{\mathrm{c}}$ & $0.549 \pm 0.026^{\mathrm{e}}$ \\
\hline
\end{tabular}

Each value represents mean \pm SD of three replicates. Within a column, means followed by the same letter are not significantly different $(\mathrm{P} \leq 0.05)$ according to Tukey Test. 
Table 2: Effect of the precursors on biomass accumulation and diosgenin content in shoot cultures of D.deltoidea

\begin{tabular}{cccc} 
Precursor $(\mu \mathrm{m})$ & Harvest time (Days) & Biomass $(\mathrm{g} \mathrm{DW})$ & Diosgenin \% \\
\hline $\begin{array}{c}\text { Squalene } \\
0\end{array}$ & 5 & $1.780 \pm 0.092^{\mathrm{a}, \mathrm{b}}$ & $0.319 \pm 0.008^{\mathrm{i}, \mathrm{j}}$ \\
100 & 5 & $1.121 \pm 0.017^{\mathrm{d}}$ & $0.947 \pm 0.021^{\mathrm{a}}$ \\
200 & 5 & $1.034 \pm 0.022^{\mathrm{d}}$ & $0.636 \pm 0.048^{\mathrm{c}}$ \\
& & & \\
0 & 10 & $1.737 \pm 0.191^{\mathrm{a}, \mathrm{b}}$ & $0.307 \pm 0.019^{\mathrm{i}}$ \\
100 & 10 & $0.736 \pm 0.019^{\mathrm{e}, \mathrm{f}}$ & $0.485 \pm 0.012^{\mathrm{e}, \mathrm{f}}$ \\
200 & 10 & $0.638 \pm 0.016^{\mathrm{g}}$ & $0.412 \pm 0.010^{\mathrm{f}, \mathrm{g}, \mathrm{h}}$
\end{tabular}

B-Sitosterol

0

100

$200 \quad 5$

$5 \quad 1.721 \pm 0.024^{\mathrm{a}, \mathrm{b}} \quad 0.315 \pm 0.014^{\mathrm{i}, \mathrm{j}}$

$5 \quad 1.559 \pm 0.025^{\mathrm{c}} \quad 0.782 \pm 0.011^{\mathrm{b}}$

$5 \quad 0.745 \pm 0.028^{\mathrm{e}, \mathrm{f}} \quad 1.006 \pm 0.001^{\mathrm{a}}$

$0 \quad 10$

$100 \quad 10$

$200 \quad 10$

Cholesterol

0

5

$1.730 \pm 0.014^{\mathrm{a}, \mathrm{b}}$

$0.313 \pm 0.013^{i, j}$

100

5

$1.032 \pm 0.017^{\mathrm{d}}$

$0.562 \pm 0.011^{\mathrm{d}}$

200

5

$0.725 \pm 0.011^{\mathrm{f}}$

$0.635 \pm 0.012^{\mathrm{C}}$

0

10

100

10

$1.777 \pm 0.019^{\mathrm{a}, \mathrm{b}}$

$0.414 \pm 0.007^{\mathrm{f}, \mathrm{g}, \mathrm{h}}$

200

10

$0.819 \pm 0.017^{\mathrm{e}}$

$0.474 \pm 0.009^{\mathrm{e}, \mathrm{f}, \mathrm{g}}$

$0.559 \pm 0.015^{\mathrm{g}, \mathrm{h}}$

$0.518 \pm 0.009^{d, e}$

Each value represents mean \pm SD of three replicates. Within a column, means followed by the same letter are not significantly different $(\mathrm{P} \leq 0.05)$ according to Tukey Test.

Table 3: Central composite design (CCD) for elicitor and precursor optimization 


\begin{tabular}{lllllll}
\hline StdOrder & $\begin{array}{l}\text { salicylic } \\
\text { acid }\end{array}$ & $\begin{array}{l}\beta \text { - } \\
\text { sitosterol }\end{array}$ & $\begin{array}{l}\text { \%Diosgenin } \\
\text { (Exp) }\end{array}$ & $\begin{array}{l}\text { \%Diosgenin } \\
\text { (Pred) }\end{array}$ & $\begin{array}{l}\text { Biomass } \\
\text { (Exp) }\end{array}$ & $\begin{array}{l}\text { Biomass } \\
\text { (Pred) }\end{array}$ \\
\hline 1 & 100 & 100 & 0.791 & 0.782 & 1.902 & 1.903 \\
2 & 200 & 100 & 1.177 & 1.164 & 1.889 & 1.885 \\
3 & 100 & 200 & 1.143 & 1.124 & 1.923 & 1.926 \\
4 & 200 & 200 & 1.115 & 1.092 & 1.912 & 1.910 \\
5 & 79.29 & 150 & 0.873 & 0.885 & 1.913 & 1.909 \\
6 & 220.71 & 150 & 1.115 & 1.133 & 1.882 & 1.885 \\
7 & 150 & 79.29 & 0.967 & 0.975 & 1.896 & 1.897 \\
8 & 150 & 220.71 & 1.145 & 1.167 & 1.934 & 1.932 \\
9 & 150 & 150 & 1.291 & 1.302 & 1.952 & 1.954 \\
10 & 150 & 150 & 1.289 & 1.302 & 1.956 & 1.954 \\
11 & 150 & 150 & 1.314 & 1.302 & 1.958 & 1.954 \\
12 & 150 & 150 & 1.321 & 1.302 & 1.953 & 1.954 \\
13 & 150 & 150 & 1.301 & 1.302 & 1.955 & 1.954 \\
\hline
\end{tabular}

Table 4A: Estimated regression coefficients for \% diosgenin and biomass

\begin{tabular}{|c|c|c|c|c|c|c|}
\hline \multirow{2}{*}{ Term } & \multicolumn{2}{|c|}{ \%diosgenin } & \multicolumn{3}{|c|}{ Biomass } & \multirow[b]{2}{*}{$\mathrm{T}$} \\
\hline & Coef & $\begin{array}{l}\text { SE } \\
\text { Coef }\end{array}$ & $\mathrm{T}$ & Coef & $\begin{array}{l}\text { SE } \\
\text { Coef }\end{array}$ & \\
\hline Constant & 1.302 & 0.009 & $141.125^{* * *}$ & 1.954 & 0.0015 & $1261.893^{* * *}$ \\
\hline salicylic acid & 0.087 & 0.007 & $11.995^{* * *}$ & -0.008 & 0.0012 & $-6.924^{* * *}$ \\
\hline$\beta$-sitosterol & 0.067 & 0.007 & $9.28^{* * *}$ & 0.012 & 0.0012 & $9.976^{* * *}$ \\
\hline salicylic acid*salicylic acid & -0.146 & 0.007 & $-18.712^{* * *}$ & -0.028 & 0.0013 & $-21.767^{* * *}$ \\
\hline$\beta$-sitosterol* $\beta$-sitosterol & -0.115 & 0.007 & $-14.75^{* * *}$ & -0.019 & 0.0013 & $-15.105^{* * *}$ \\
\hline salicylic acid* $\beta$-sitosterol & -0.103 & 0.01 & $-10.029^{* * *}$ & 0.0005 & 0.017 & $0.289^{\mathrm{NS}}$ \\
\hline
\end{tabular}

P-value $* * *>0.01, * *>0.05$

Table 4B: Analysis of variance for diosgenin yield and biomass

\begin{tabular}{|c|c|c|c|c|c|c|c|c|c|}
\hline \multirow[t]{2}{*}{ Source } & \multicolumn{4}{|c|}{ \% diosgenin } & \multicolumn{5}{|c|}{ Biomass } \\
\hline & $\mathrm{DF}$ & $\begin{array}{l}\text { Seq } \\
\text { SS }\end{array}$ & Adj SS & $\begin{array}{l}\text { Adj } \\
\text { MS }\end{array}$ & $\bar{F}$ & $\begin{array}{l}\text { Seq } \\
\text { SS }\end{array}$ & $\begin{array}{l}\text { Adj } \\
\text { SS }\end{array}$ & $\begin{array}{l}\text { Adj } \\
\text { MS }\end{array}$ & $\bar{F}$ \\
\hline Regression & 5 & 0.355 & 0.355 & 0.071 & $166.98^{* * *}$ & 0009 & 0009 & 0.001 & $154.89^{* * *}$ \\
\hline Linear & 2 & 0.097 & 0.097 & 0.048 & $115.00^{* * *}$ & 0.001 & 0.001 & 0.0008 & $73.74^{* * *}$ \\
\hline Square & 2 & 0.214 & 0.214 & 0.107 & $252.14^{* * *}$ & 0.007 & 0.007 & 0.003 & $313.44^{* * *}$ \\
\hline Interaction & 1 & 0.042 & 0.042 & 0.042 & $100.59^{* * *}$ & 0.000 & 0.000 & 0.000 & $0.08^{\mathrm{NS}}$ \\
\hline $\begin{array}{l}\text { Residual } \\
\text { Error }\end{array}$ & 7 & 0.002 & 0.002 & 0.0004 & & 0.000 & 0.000 & 0.000 & \\
\hline Lack-of-Fit & 3 & 0.002 & 0.002 & 0.0007 & $3.74^{\mathrm{NS}}$ & 0.000 & 0.000 & 0.000 & $3.58^{\mathrm{NS}}$ \\
\hline Pure Error & 4 & 0.0007 & 0.0007 & 0.0001 & & 0.000 & 0.000 & 0.000 & \\
\hline Total & 12 & 0.358 & & & & 0.009 & & & \\
\hline
\end{tabular}


P-value ${ }^{* * *}>0.01, * *>0.05$

\section{Figures}
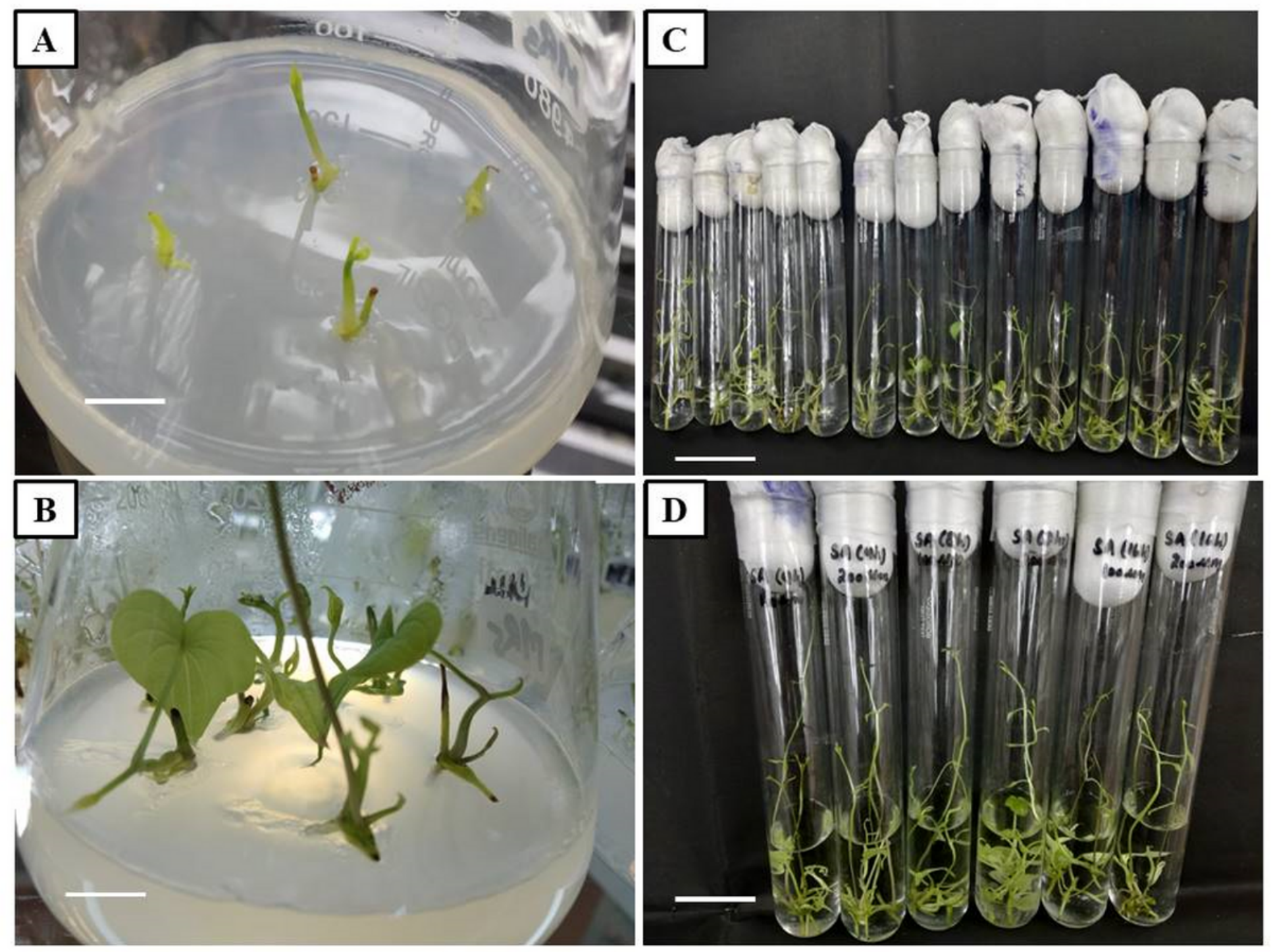

Figure 1

Stages of tissue culture in D. deltoidea (A) shoot initiation in 1 week of culture in MS medium supplemented with BAP and IBA (B) shoot proliferation and multiplication after 2 weeks (C) regenerants sub-cultured in liquid MS medium after 21 days of inoculation (D) treated regenerants. 

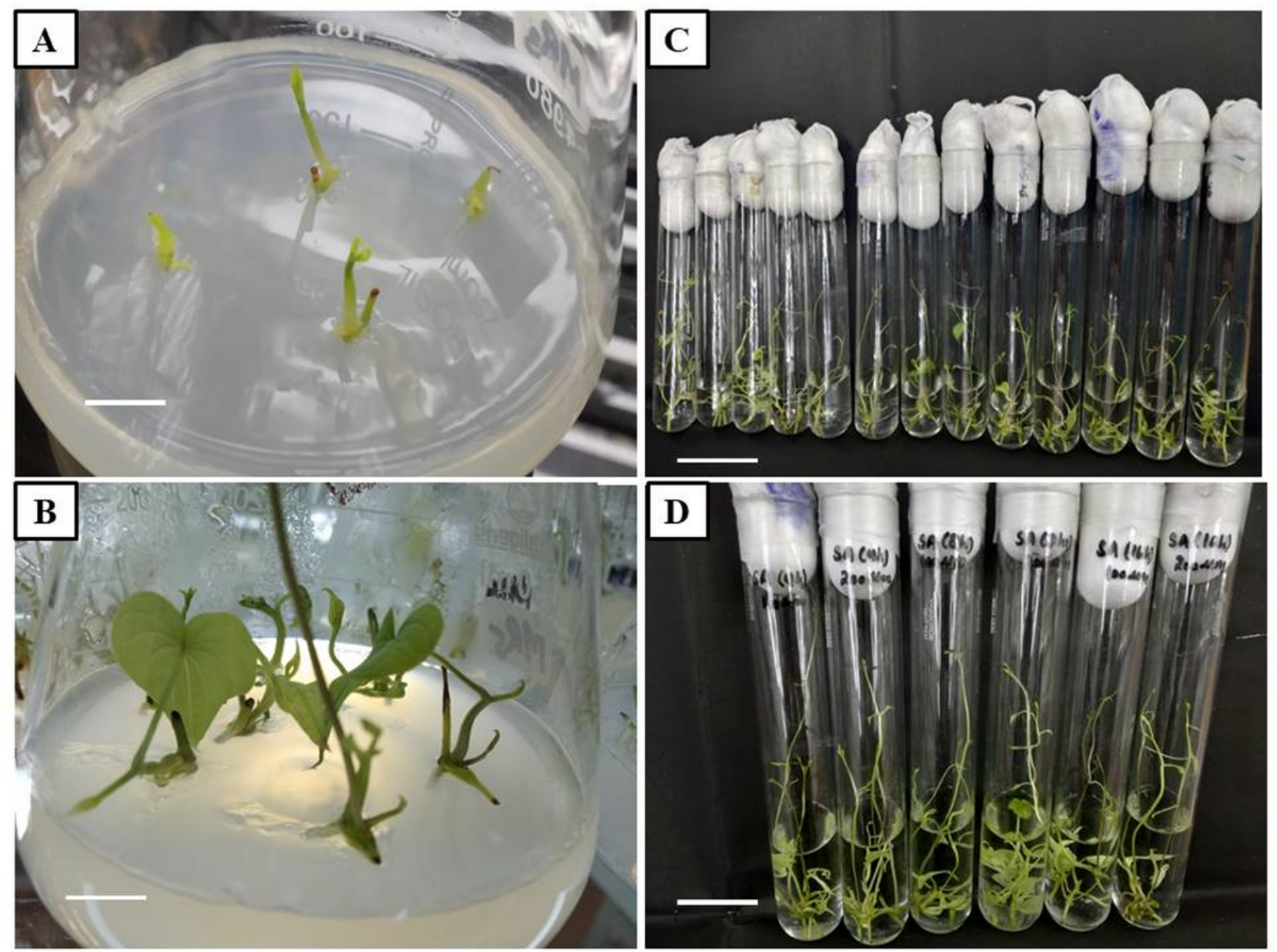

Figure 1

Stages of tissue culture in D. deltoidea (A) shoot initiation in 1 week of culture in MS medium supplemented with BAP and IBA (B) shoot proliferation and multiplication after 2 weeks (C) regenerants sub-cultured in liquid MS medium after 21 days of inoculation (D) treated regenerants. 

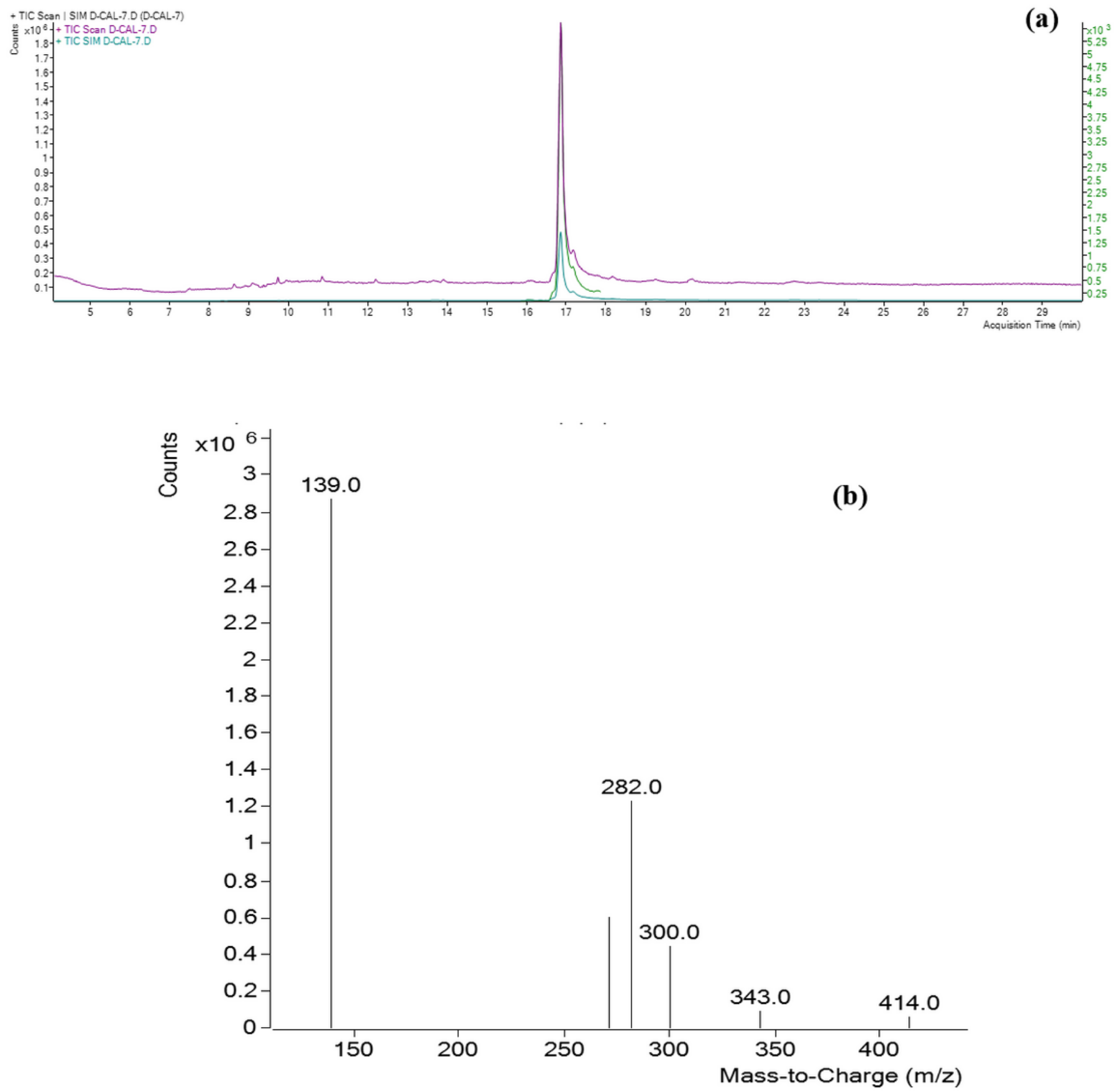

Figure 2

TIC (a) and SIM (b) chromatograms of diosgenin 

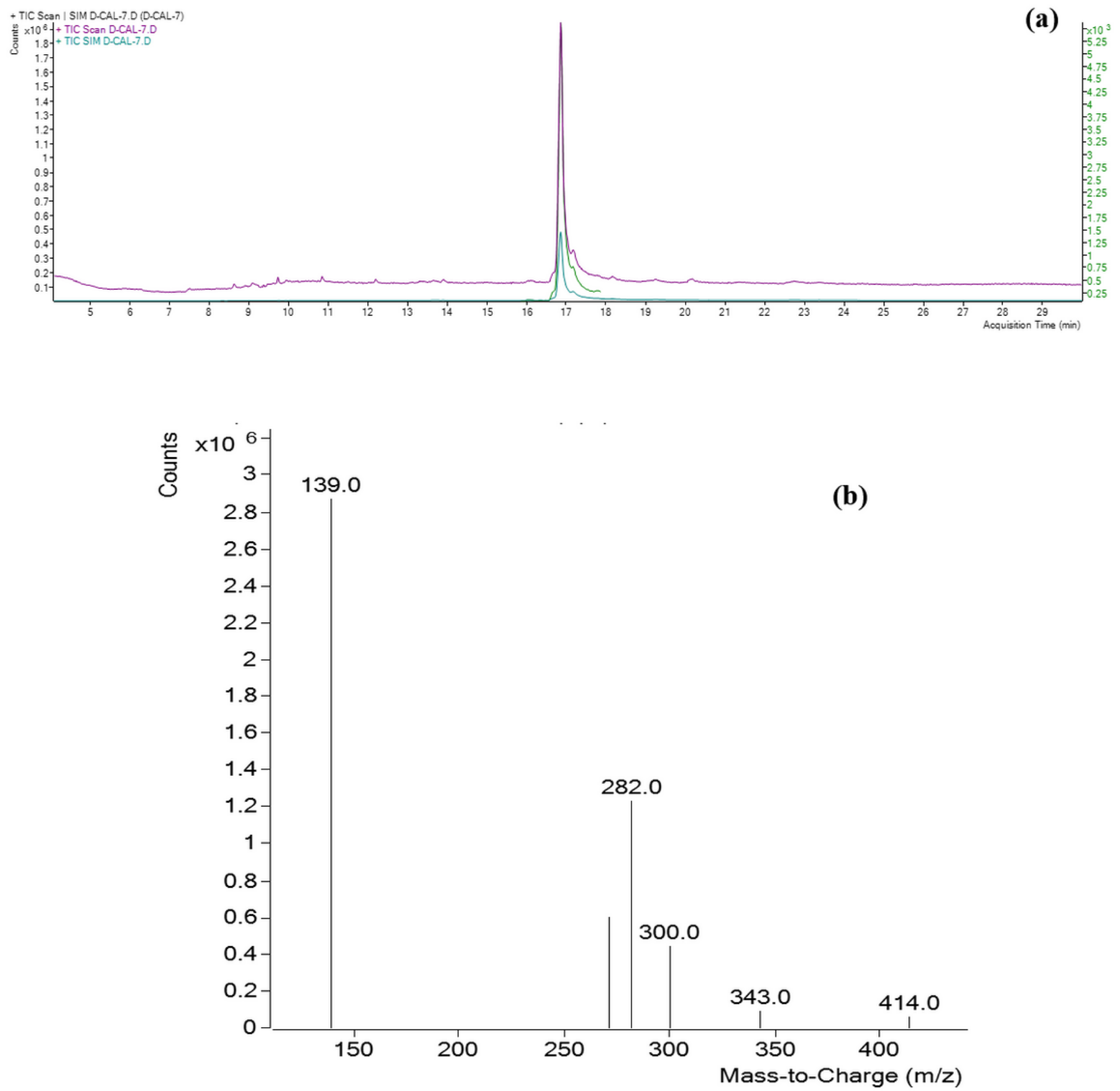

Figure 2

TIC (a) and SIM (b) chromatograms of diosgenin 


\section{Contour Plot of \%Diosgenin vs ß-sitosterol, salicylic acid}
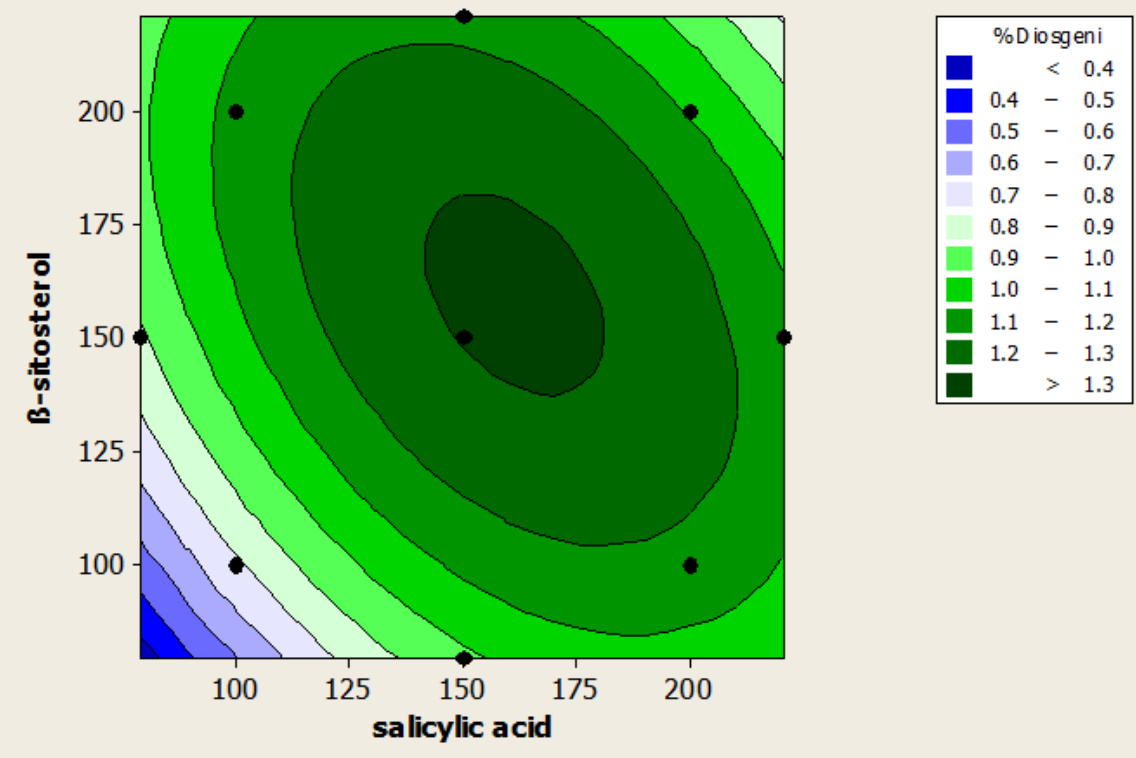

A

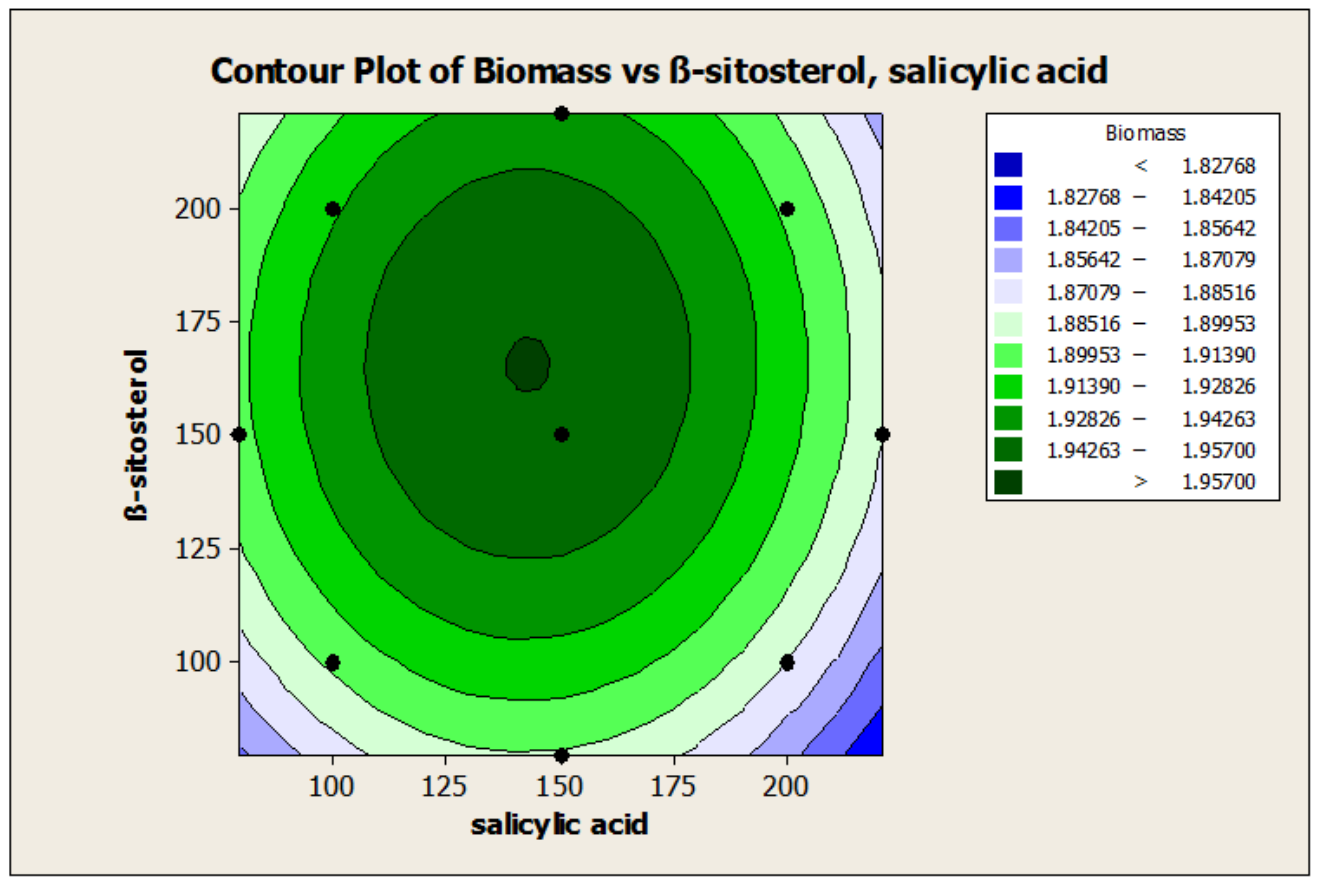

B

Figure 3

A: Contour plot for diosgenin yield B: Contour plot for biomass yield 


\section{Contour Plot of \%Diosgenin vs ß-sitosterol, salicylic acid}
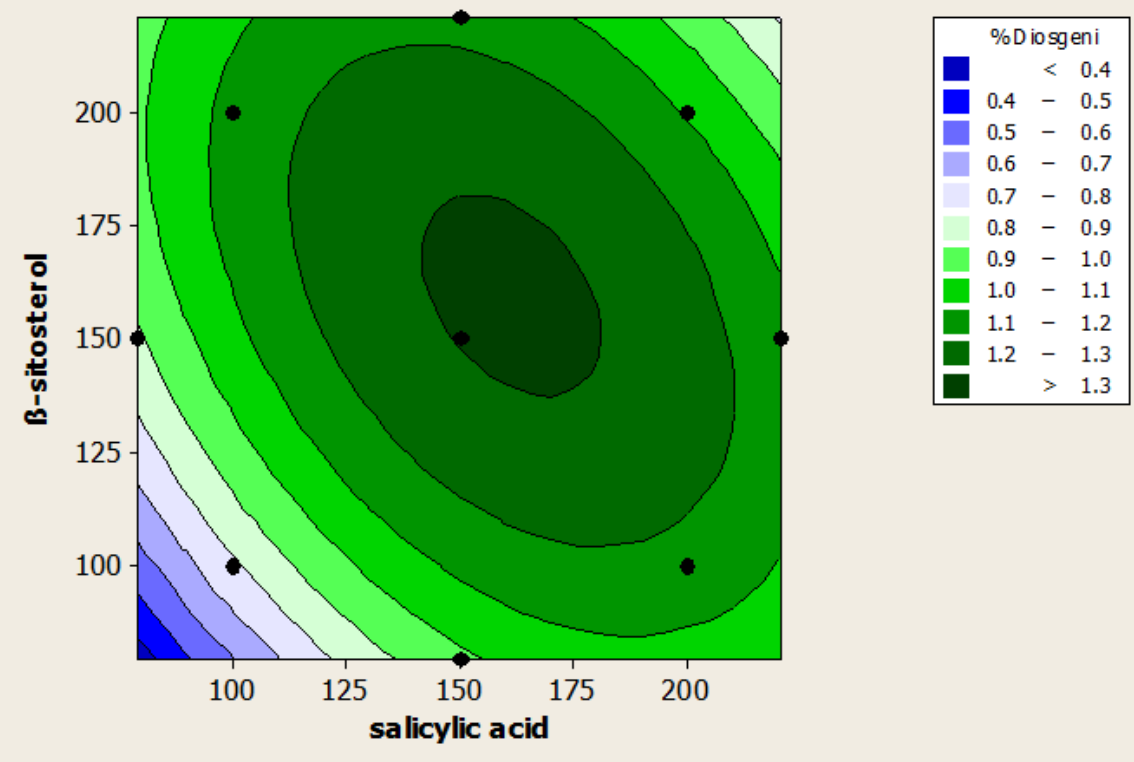

A

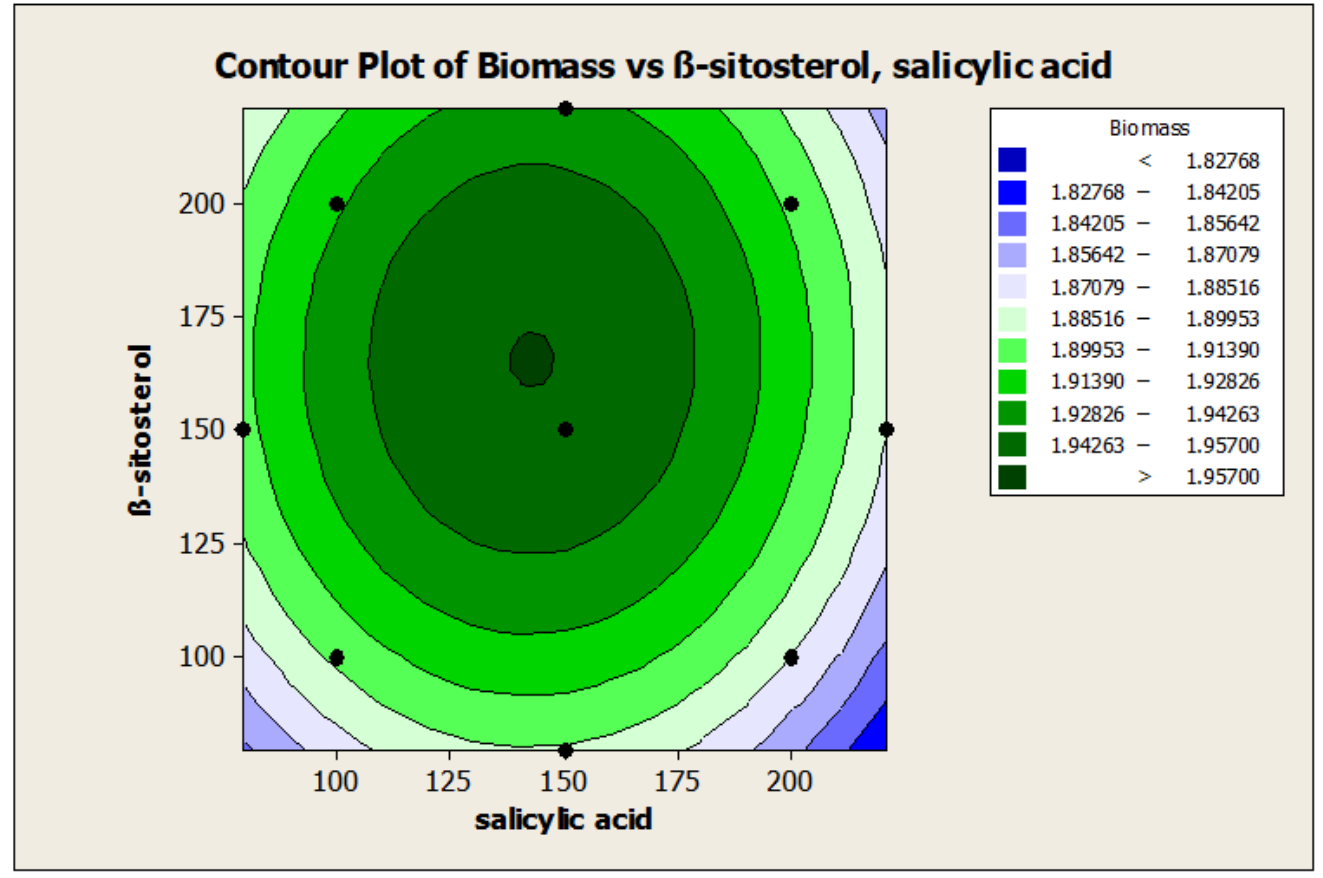

B

Figure 3

A: Contour plot for diosgenin yield B: Contour plot for biomass yield

\section{Supplementary Files}

This is a list of supplementary files associated with this preprint. Click to download. 
- Graphicalabstract.pptx

- Graphicalabstract.pptx 